\title{
Building Communities of Engineering Faculty, Staff, and Students Engaged in Educational Research: The Approach of UGA's Engineering Education Transformations Institute
}

\author{
John R. Morelock \\ University of Georgia \\ Nicola W. Sochacka \\ University of Georgia \\ Joachim Walther \\ University of Georgia
}

We summarize the work of the University of Georgia's Engineering Education Transformations Institute (EETI) in cultivating communities of faculty, staff, and students engaged in educational research. EETI leadership draws upon Donella Meadows' 14 principles for engineering change from within a system and industry-vetted practices for establishing collective intelligence in teams to create four conditions that have led to successful, enduring, and diverse communities: Value-oriented communication, inclusive relationship-building, collective intelligence development, and process-oriented expectations. In these communities, participants from a variety of academic levels (students; staff; pre-tenure, tenured, instructional, and professional-track faculty) develop ideas and projects together in a collaborative process.

Keywords: organizational development, educational development, institutional change, discipline-based educational research, engineering education

\section{INTRODUCTION}

While engaging engineering faculty in educational research has long been a central topic of engineering education (ENED) literature (Streveler, Borrego, \& Smith, 2007; Wankat, Felder, Smith, \& Oreovicz, 2002), intentional efforts to engage engineering faculty in ENED research are particularly relevant today. A foundational literature review of STEM instructional change strategies by Henderson, Beach, and Finkelstein (2011) highlighted the need for change agents to transition away from dissemination-focused strategies and toward the development of reflective instructors to promote instructional change in individuals. Educational research provides an important avenue in developing instructional reflection skills, as it provides structured methods to study and iterate upon educational innovations (Carlisle \& Weaver, 2018; Draeger, 2013), among other benefits for building instructional change culture and communities (Carlisle \& Weaver, 2018). The value of educational research for engineering and other STEM faculty has 
been recognized by funding organizations like NSF, which recently launched solicitations for ECR: Building Capacity in STEM Education Research (BCSER) and PFE: Research Initiation in Engineering Formation (RIEF), both of which focus on building educational research skills for technical faculty. The availability of these funding opportunities coupled with the known benefits of faculty engaging in educational research point to the importance of incorporating ENED research into engineering faculty development programming.

This paper summarizes the work and results of the Engineering Education Transformations Institute (EETI) in cultivating a growing community of technical engineering faculty, staff, and graduate students engaged in educational research. EETI was founded in early 2017 to promote and sustain a culture of engineering education scholarship and innovation that reaches across all programs in the University of Georgia's College of Engineering, which was founded in 2012. EETI has since partnered with several offices across campus to produce award-winning programming that helps connect engineering faculty with their peers around the scholarship and practice of teaching and learning. Today, EETI supports the College's approximately 100 faculty, 40 staff, and 150 graduate students with programs spanning educational innovation, ENED research, mentoring, teaching support, and ENED conference travel. A more comprehensive overview of EETI's formation, programming, and theoretical inspirations can be found elsewhere (Morelock, Walther, \& Sochacka, 2019; Secules, Bale, Sochacka, \& Walther, 2018).

For the purposes of this paper, we will focus on EETI programming directly related to ENED research, which we define as the systematic study of ENED settings-including the Scholarship of Teaching and Learning (SOTL) - that has salient implications for ENED research and practice beyond the study's context. We are aware of other frameworks that delineate between SOTL and discipline-based research educational based on the degree of methodological rigor (e.g., Streveler et al., 2007), but we consider that distinction to establish barriers to entry that are antithetical to the goal of onboarding engineering faculty to ENED research. Our ENED research programming includes:

1. ENED research incubator - Weekly meetings where EETI leadership helps faculty translate their ENED research project ideas into opportunities for grant proposals and/or publications. Our Fall 2019 research incubator garnered 12 participants spanning a wide range of roles (2 tenure-track faculty, 4 lecturers, 3 professional-track faculty, 1 advising staff member, 1 graduate student, and 1 administrator.)

2. Research initiation and development grants - EETI leadership provides mini-grants to faculty to help them initiate or pilot ENED research in preparation for grant proposals. Since its inception, EETI has awarded $\$ 78,000$ worth of research initiation funds, with $\$ 68,000$ of that amount being awarded in Spring 2019 in coordination with a larger seed grant initiative at the university level.

The remainder of this paper describes the guiding frameworks and consequent research-based practices that EETI uses to encourage faculty participation and community building around ENED research.

\section{GUIDING FRAMEWORKS}

EETI's primary mission is to leverage complex systems theory to develop community-focused programming that cultivates an institutional culture of continuous improvement around engineering teaching and learning. To summarize our prior work on how complex systems theory is used to inform our faculty development approach (Morelock et al., 2019), EETI's leadership considers our College's social environment to be a complex system and strives to make decisions in accordance with Donella Meadows' 14 principles for engendering change from within a system (Meadows, 2008). These principles were developed by Meadows and published posthumously as a synthesis of lessons learned in her work as an internationally renowned systems analyst for over 30 years. Several of these principles have direct implications for how we conduct our ENED research work; these principles and implications are summarized in Table 1. 


\section{TABLE 1 \\ SYSTEMS CHANGE PRINCIPLES (MEADOWS, 2008) THAT INFORM EETI'S ENED RESEARCH WORK}

\begin{tabular}{|l|l|l|}
\hline Principle & Description of Principle & Implications for ENED Research Work \\
\hline $\begin{array}{l}\text { Don't erode the } \\
\text { goal of } \\
\text { goodness }\end{array}$ & $\begin{array}{l}\text { Cynicism in system actors breeds } \\
\text { poor system performance. Uphold } \\
\text { system ideals and maintain high } \\
\text { expectations for system actors. }\end{array}$ & $\begin{array}{l}\text { Assume faculty are excited and willing to } \\
\text { engage with ENED research when } \\
\text { recruiting. After recruitment, focus on } \\
\text { maintaining the excitement of those who } \\
\text { participate. }\end{array}$ \\
\hline $\begin{array}{l}\text { Go for the good } \\
\text { of the whole }\end{array}$ & $\begin{array}{l}\text { Seek to optimize the whole system, } \\
\text { rather than individual parts. }\end{array}$ & $\begin{array}{l}\text { Focus on building a supportive, } \\
\text { longstanding ENED research community } \\
\text { and on the benefits of the ENED research } \\
\text { process, rather than on immediate } \\
\text { outcomes and deliverables (publications, } \\
\text { grant proposals, etc.) }\end{array}$ \\
\hline $\begin{array}{l}\text { Use language } \\
\text { with care and } \\
\text { enrich it with } \\
\text { system concepts }\end{array}$ & $\begin{array}{l}\text { The language used by system actors } \\
\text { signifies what behaviors are valued } \\
\text { within the system. Consistently use } \\
\text { language that aligns with desired } \\
\text { system behavior. }\end{array}$ & $\begin{array}{l}\text { Lead with excitement in all } \\
\text { communications with faculty. } \\
\text { Communicate the value of engineering } \\
\text { education research. Emphasize our focus } \\
\text { on community-building and processes } \\
\text { rather than outcomes. }\end{array}$ \\
\hline $\begin{array}{l}\text { Defy the } \\
\text { disciplines }\end{array}$ & $\begin{array}{l}\text { Systems often stretch across } \\
\text { disciplinary lines. Learning about } \\
\text { and changing a system requires } \\
\text { crossing those lines and taking an } \\
\text { interdisciplinary approach. }\end{array}$ & $\begin{array}{l}\text { Encourage participation from all College } \\
\text { actors, regardless of rank, role, or } \\
\text { engineering discipline }\end{array}$ \\
\hline $\begin{array}{l}\text { Celebrate } \\
\text { complexity }\end{array}$ & $\begin{array}{l}\text { Embrace the system instead of trying } \\
\text { to force change. Encourage diversity, } \\
\text { self-organization, and disorder. }\end{array}$ & $\begin{array}{l}\text { Adapt to participant interests and let them } \\
\text { lead discussions. We are here to facilitate } \\
\text { and build community, not take the reins. }\end{array}$ \\
\hline
\end{tabular}

Meadows' principles help EETI leadership ensure that our actions help the communities we build align with our values for the engineering education ecosystem we seek to cultivate-one that is passionate about and involved with engineering teaching and learning. However, in terms of the day-to-day practices we use in building and maintaining a cohesive ENED research community, we turn to a framework that is more explicit in its actionable recommendations: Behaviors of collectively intelligent teams found by Woolley, Chabris, Pentland, Hashmi, and Malone (2010). Collective intelligence refers to a team's capacity to productively learn and solve problems together, which is important in developing a cohesive and supportive ENED research community. Woolley et al. (2010) found that, in addition to diversity within the team, collective intelligence was highly influenced by conversational turn-taking and social sensitivity. Conversational turn-taking refers to the equal distribution of communication among a team-i.e., no team members dominate the conversation, and effort is made to include all team members in the conversation. Social sensitivity — which can be colloquially referred to as empathy - refers to the capacity of the team members to recognize and empathize with the thoughts and feelings of other members. Industry giants such as Google have since leveraged these two behaviors of collectively intelligent teams to improve team productivity (Duhigg, 2016). Likewise, EETI leadership facilitates our ENED research communities to encourage these behaviors. 


\section{BUILDING COMMUNITY: RECOMMENDATIONS FOR APPLYING OUR GUIDING FRAMEWORKS TO PRACTICE}

EETI leveraged our experiences applying these two guiding frameworks to develop four recommendations for developing engineering ENED research communities:

1. Use language carefully to communicate the value of ENED research and your excitement to work with the community.

2. Develop collective intelligence via conversational turn-taking and socially sensitive responses.

3. Establish process-oriented expectations that prioritize the development of ideas and projects rather than products and publications.

4. Build relationships in a way that transcends academic hierarchies and accommodates new participants.

The remainder of this section expands on each of these four recommendations, providing examples of how we have modeled them in the recent past.

\section{Use Language Carefully to Communicate the Value of ENED Research and Your Excitement to Work With the Community}

It can be easy for faculty to developers to see higher education incentive systems that prioritize research over teaching and assume that most engineering faculty do not care to engage with teaching and learning. However, one of Meadows' Principles, "Don't erode the goal of goodness," emphasizes that system actors tend to rise to the expectations that leaders and colleagues set for them. Based on this principle, if we (as faculty developers) approach faculty with the expectation that our job is to overcome their resistance to participation, then we are more likely to encounter that resistance because we are complicit in maintaining resistance as a norm. Accordingly, in keeping with another of Meadows' principles, "Use language with care and enrich it with system concepts," EETI's leadership approaches communication with engineering faculty, staff, and students with the message that we are excited to work with them on ENED research projects, and appeal to the idea that they might find such an opportunity exciting too. We are especially careful to lead with excitement when we send semesterly emails soliciting participants for our ENED research incubator and applications for our research initiation grants. While we recognize it would be naïve to expect all of our faculty to giddily join our ENED research bandwagon, we find that our attitude has gone a long way toward helping people who are excited to develop a sense of belonging in our communities.

While excitement is important for the recruitment of participants, we have found that communicating the value of engineering education research is important in retaining these participants. Most engineering faculty come from technical research backgrounds and often struggle to recognize the value of social science research paradigms without help (Borrego, 2007). EETI leadership finds this struggle manifests most often as an expectation that ENED research is a more systematic method of conducting course assessment or program evaluation. For example, when we asked one pair of new research incubator participants what kinds of research questions they wanted to address regarding a new degree program they had started, we noticed that they focused on formative evaluation programs that would help them improve the program. In response, we spent a chunk of that incubator meeting emphasizing the difference between evaluation questions and educational research questions: The former is meant to improve the program, while the latter is meant to generate knowledge that advances engineering education as a field. We were careful to specify that both are valuable and can share methods, but that they have different goals and levels of usefulness to other educators. As a result of this conversation, this pair of participants emerged not only with a greater appreciation of engineering education research but also a renewed excitement to figure out how their program could advance knowledge beyond their own university's context.

\section{Develop Collective Intelligence via Conversational Turn-Taking and Socially Sensitive Responses}

As we discussed in the preceding section, building collective intelligence is an important step in fostering productive ENED research communities. Accordingly, EETI leadership takes action to ensure that 
our research communities develop collective intelligence, starting by ensuring that participants take turns during ENED research conversations. In inappropriately managed meetings, we have found that "knowledge holders"- people with expertise in educational research-can dominate ENED research conversations in an attempt to transfer their wisdom and experience to the community. While these knowledge holders certainly bring value to conversations, our philosophy is that a research incubator is an opportunity to make all participants feel like knowledge holders. After all, every participant-instructors, students, and staff-has developed wisdom in at least some facet of their educational context by being actively involved in the educational process through their job. Accordingly, an important role of EETI leadership is to help less traditional knowledge holders - especially staff and students—recognize the value they bring to the ENED research community by actively soliciting their opinions and knowledge during conversations. We have found that intentionally and regularly bringing these participants into the discussion is crucial to developing their sense of belonging in ENED research communities, and consequentially in maintaining diverse and stable research cohorts over time.

Empathizing with participants and meeting them at their current level of knowledge and comfort around educational research is another important component of building collective intelligence. For example, when the pair of faculty mentioned in the preceding subsection were brainstorming research questions they could ask to generate knowledge around their new degree program, one of them was heavily invested in asking questions that established direct, quantitative causal links, such as "Does participating in the degree program lead to higher engineering degree programs?" Being social scientists, EETI leadership knew that establishing such causation quantitatively would be extremely difficult, given the new degree program's relatively low cohort size and the self-selecting nature of student participation in this program (Singleton $\&$ Straits, 2010). However, we also recognized that this faculty member was most comfortable with experimental designs given his technical background, and that rejecting his research questions outright might lead him to withdraw from the conversation. Instead, we found it more productive to initiate a discussion on the advantages and disadvantages of different educational research methods, during which the faculty member was able to recognize the limitations of his proposed research method on his own, after which point he was more open to the idea of alternative methodologies. Eventually, this pair of faculty members decided on a mixed methods research approach that satisfied their desire for quantitative, statistically valid data, while also allowing them to qualitatively answer interesting questions about students' motivation to participate in the degree program that would be difficult to investigate quantitatively.

\section{Establish Process-Oriented Expectations That Prioritize the Development of Ideas and Projects Rather Than Products and Publications}

EETI leaders are, first and foremost, research faculty. While a significant portion of our jobs is running ENED research activities, we are ultimately evaluated on our publications and grants, many of which come from our collaboration with faculty, staff, and students on ENED research projects. However, one of Meadows' Principles, "Go for the good of the whole," emphasizes that if we put our personal objectives (the need to publish and get grants) above the needs of our ENED research communities as a whole, the entire system would suffer. Many of the participants who join our research incubators or apply for our research initiation grants have little experience with educational research, and initially lack the confidence that they are ready to publish or apply for grants in engineering education. Accordingly, EETI leadership has found it important to frame our ENED research communities as spaces to experiment, grow, and develop skills and confidence in educational research as part of a supportive community.

We adopted this approach based on existing research in pursuit of two major goals. First, by focusing on process over product, we aim to help participants maintain a positive attitude and develop intrinsic motivation for ENED research - if a publication or proposal gets rejected, a focus on process frames the rejection as a common and shameless chance to learn and improve, rather than a failure to achieve a primary objective. This outcome aligns with the literature on self-determination theory and intrinsic motivation, where researchers have found that external rewards (e.g., accepted publications and awarded proposals) are detrimental to intrinsic motivation unless acquired in a context that is fully supportive of participants' sense 
of autonomy (Deci \& Moller, 2005). Second, in supporting our participants' autonomy, we find that many participants decide to publish or apply for grants on their own accord, creating a better system both that meets both our personal objectives and the needs of the ENED research community as a whole. This outcome also aligns with self-determination theory, which asserts that autonomy-supporting behavior is essential to helping others develop intrinsic motivation (Deci \& Ryan, 2000).

\section{Build Relationships in a Way That Transcends Academic Hierarchies and Accommodates New Participants}

We find that maintaining a diverse community of ENED researchers has many advantages. First, diverse participation is another factor that Woolley et al. (2010) found to increase collective intelligence, promoting a more effective team. Second, a diverse range of participants means that word of the inclusivity of our ENED research communities passes between College personnel, encouraging a wider range of people to participate. We have seen the latter benefit manifest as administrators successfully encouraging their advising staff to participate and as tenure-track faculty recommending their graduate student advisees to participate, among other manifestations.

The level of diversity we have achieved in our research incubator was the result of intentional efforts to highlight the contributions and interests that each participant can bring to the group and by making accommodations to ensure people who are new and interested can participate. We accomplish the former by getting to know each faculty member personally through their engineering education research interestsvalidating their interests through developing their projects and connecting them with relevant literature and research communities - and by modeling conversational turn-taking (see the second recommendation above.) As an example of the latter, there was a lecturer who wanted to participate in our research incubator in 2019, but who was not available to attend during times that more longstanding members were available to meet. To reconcile this problem, EETI leadership created a separate event-ENED research "office hours"-during which this lecturer would be able to attend and work with our leadership to develop his ENED research ideas. Although we could not fully integrate this lecturer into our existing ENED research community, his experiences during office hours were positive, and we are optimistic he will attend future research incubators as his schedule allows. These behaviors embrace two more of Meadows' principles: "Celebrate diversity" and "Defy the disciplines."

\section{BENEFITS OF BUILDING ENED RESEARCH COMMUNITIES FOR FACULTY MEMBERS AND STAFF}

In the introduction of this paper, we reviewed research on the benefits of ENED research engagement for instructional change in engineering and other STEM disciplines. Our experience also leads us to believe that ENED research could have benefits for the retention of a broad range of faculty and staff not typically foregrounded in educational literature, including senior faculty, administrators, lecturers, professional track faculty, and advisors. In particular, ENED research offers faculty and staff who are not otherwise heavily involved in research-but almost all of whom have a Ph.D. - an outlet for their intellectual curiosity that synergizes with their primary job functions (advising, program development, teaching, etc.) We have observed ENED research revitalizing the curiosity of senior faculty members no longer conducting research in their technical areas; providing lecturers, professional-track faculty, and administrators a chance to develop their research skills in a way that enhances their roles rather than distracting from them; and allowing advising staff to contribute valuable knowledge to their broader communities (e.g., the National Academic Advising Association.) As future work, we would like to follow up with these participants in a more formal qualitative study to determine if their experiences have been as impactful as our anecdotal observations suggest. 


\section{CONCLUSION AND IMPLICATIONS FOR FACULTY DEVELOPMENT}

While the prevalence of educational research programming has increased over the last decade, it is still not a high priority for many faculty development leaders (Beach, Sorcinelli, Austin, \& Rivard, 2016). In writing this paper, we hoped to provide compelling evidence for the benefits of educational research in an engineering context and provide a set of guiding frameworks and concrete recommendations for developing supportive educational research communities. We believe these recommendations are transferable to a wide range of institutional contexts and would be interested to hear about outcomes at other faculty development units that decide to apply them. While engaging engineering faculty, staff, and students with educational research may seem daunting at first, we can make that notion much more auspicious through communications of excitement and value, a focus on low-stakes processes and learning opportunities, and intentional efforts to develop collective intelligence in an inclusive and diverse community.

For readers interested in learning more about EETI's ENED research initiatives and other programming, a comprehensive and current catalog of our programs is publicly available online in the form of a nomination portfolio for a statewide, program-level teaching award (Engineering Education Transformations Institute, 2019).

\section{ACKNOWLEDGEMENT}

(C2020 American Society for Engineering Education. ASEE Annual Conference Proceedings, June 2020, Virtual Conference

\section{REFERENCES}

Beach, A.L., Sorcinelli, M.D., Austin, A.E., \& Rivard, J.K. (2016). Faculty development in the age of evidence: Current practices, future imperatives. Sterling, VA: Stylus Publishing.

Borrego, M. (2007). Conceptual difficulties experienced by trained engineers learning educational research methods. Journal of Engineering Education, 96(2), 91-102. doi:10.1002/j.21689830.2007.tb00920.x

Carlisle, D.L., \& Weaver, G.C. (2018). Stem education centers: Catalyzing the improvement of undergraduate stem education. International Journal of STEM Education, 5(1), 47. doi:10.1186/s40594-018-0143-2

Deci, E.L., \& Moller, A.C. (2005). The concept of competence: A starting place for understanding intrinsic motivation and self-determined extrinsic motivation. In A.J. Elliot \& C.S. Dweck (Eds.), Handbook of competence and motivation (pp. 570-597). New York: Guilford Press.

Deci, E.L., \& Ryan, R.M. (2000). The" what" and" why" of goal pursuits: Human needs and the selfdetermination of behavior. Psychological Inquiry, 11(4), 227-268.

Draeger, J. (2013). Why bother with the scholarship of teaching and learning? InSight: A Journal of Scholarly Teaching, 8, 12-19.

Duhigg, C. (2016, February 25). What google learned from its quest to build the perfect team. The New York Times. Retrieved from https://www.nytimes.com/2016/02/28/magazine/what-googlelearned-from-its-quest-to-build-the-perfect-team.html. Archived at https://perma.cc/6LH4-49KX.

Engineering Education Transformations Institute. (2019). Application for the regents' teaching excellence award for department or program. Retrieved from https://www.usg.edu/assets/faculty_affairs/documents/EETI_DepartmentProgramAward.pdf. Archived at https://perma.cc/5KME-E96X.

Henderson, C., Beach, A., \& Finkelstein, N. (2011). Facilitating change in undergraduate stem instructional practices: An analytic review of the literature. Journal of Research in Science Teaching, 48(8), 952-984. doi:https://doi.org/10.1002/tea.20439

Meadows, D.H. (2008). Thinking in systems: A primer (D. Wright Ed.). White River Junction, VT: Chelsea Green Publishing. 
Morelock, J.R., Walther, J., \& Sochacka, N.W. (2019). Academic change from theory to practice: Examples from UGA's engineering education transformations institute. Paper presented at the ASEE Annual Conference \& Exposition, Tampa, FL.

Secules, S., Bale, J.J., Jr., Sochacka, N.W., \& Walther, J. (2018). Examining a novel theory-to-practice effort in engineering education through multiple theoretical lenses of systems and change. Paper presented at the 2018 ASEE Annual Conference \& Exposition, Salt Lake City, UT.

Singleton, R., \& Straits, B.C. (2010). Approaches to social research. Oxford University Press.

Streveler, R.A., Borrego, M., \& Smith, K.A. (2007). 9: Moving from the scholarship of teaching and learning to educational research: An example from engineering. Wiley Online Library, 25(1), 139-149. doi:10.1002/j.2334-4822.2007.tb00479.x

Wankat, P.C., Felder, R.M., Smith, K.A., \& Oreovicz, F.S. (2002). The scholarship of teaching and learning in engineering. In M.T. Huber \& S.P. Morreale (Eds.), Disciplinary styles in the scholarship of teaching and learning: Exploring common ground (pp. 217-237). Washington, D.C.: American Association for Higher Education.

Woolley, A.W., Chabris, C.F., Pentland, A., Hashmi, N., \& Malone, T.W. (2010). Evidence for a collective intelligence factor in the performance of human groups. Science, 330(6004), 686-688.

doi:10.1126/science.119314t 